Research Article

\title{
Damping Characteristics of Metal Rubber in the Pipeline Coating System
}

\author{
Kun Xiao, Hongbai Bai $\mathbb{D}^{D}$, Xin Xue $\mathbb{D}^{D}$, and Yiwan Wu \\ Engineering Research Center for Metal Rubber, School of Mechanical Engineering and Automation, Fuzhou University, \\ Fuzhou 350116, China \\ Correspondence should be addressed to Xin Xue; xin@fzu.edu.cn
}

Received 9 July 2018; Accepted 17 October 2018; Published 6 November 2018

Academic Editor: Angelo Marcelo Tusset

Copyright (c) 2018 Kun Xiao et al. This is an open access article distributed under the Creative Commons Attribution License, which permits unrestricted use, distribution, and reproduction in any medium, provided the original work is properly cited.

\begin{abstract}
The reduction of vibration in submarine pipeline systems at high temperatures has always been a difficult problem. This paper aims to reduce the vibration of pipeline systems by using coated metal rubber. A theoretical model of the cladding damping structure, formed on the basis of the bilinear hysteresis model, is established. The mechanical model of the single degree of freedom hysteretic system is linearly equivalent to using the linearization method. The theoretical analysis indicates that the regularity of the stiffness of metal rubber decreases, and the damping increases, with the increase of the excitation amplitude. Experimental verification confirmed this analysis after an experimental system for pipelines coated by metal rubber was developed. A method for preparing the thin sheet of metal rubber, which is the damping layer, was introduced. At the same time, the force transfer rate and the structural loss factor were proposed to characterize the damping performance of the cladding damping structure. The vibration absorption characteristics of the cladding damping structure, along with its forming density, number of coating layers, and excitation magnitude, are investigated by means of the experimental method. The results indicate that the damping performance of metal rubber decreases with the increase of forming density, and the damping performance of metal rubber increases with the increase of the number of cladding layers and the magnitude of excited vibration.
\end{abstract}

\section{Introduction}

Pipelines are widely used in defense equipment and the marine industry, especially in warships, where a pipeline is often directly connected to the power device $[1,2]$. Vibrations significantly affect this pipeline, for instance, the noise created by vibrations can affect the hidden nature of ship work. Eventually, this can lead to the breakdown of the pipeline or inestimable losses to the warship.

Generally, there are two methods of vibration and noise control in pipelines: the suppression of the vibration source and the disconnection of the vibration transmission. At present, there are two kinds of connection modes in the narrow space of pipelines: rigid connections and damping connections. There are also suspension damper connections and cladding damping pipe connections in pipe vibration damping. Metal rubber is made by twisting wire into a spiral coil, winding the spiral coil according to a certain process, and finally cold stamping it [3]. Metal rubber is a typical nonlinear material, and it has an obvious hysteresis characteristic $[4,5]$. It is a good damping material because of its vibration absorption performance. Its energy dissipation and vibration absorption characteristics are not only affected by its own internal properties [6-9], including wire diameter and mass density and the blank winding mode and angle, but are also related to external conditions such as the vibration magnitude, loading amplitude, ambient temperature, and so on $[10,11]$. Cai et al. [12] studied the influence of the rubber damping structure on the vibration absorption characteristics of a ship pipeline. Their results showed that rubber damping has an obvious damping performance compared with a rigid connection. Under high temperatures, the properties of rubber will be seriously affected, which directly reduces its vibration absorption. This is because rubber is a natural polymer material which cannot be made resistant to high temperatures. Ao et al. [13] undertook 
corresponding efforts to investigate the damping performance of a metal rubber damper supporting an engine pipeline. The results indicated that the metal rubber damper had a good dry friction damping performance.

The vibration of the warship pipeline has an inestimable effect on the ship hull, so studying pipeline vibration reduction is particularly important. In this paper, a theoretical model of the cladding damping structure, on the basis of the bilinear hysteresis model, is established. The nonlinear, variable stiffness, and variable damping properties of metal rubber materials are proposed and verified by experiments. The energy dissipation characteristics of metal rubber and the effects of the coating layer number, the exciting force, and the density of the cladding layer on the vibration absorption performance of the pipeline cladding damping structure are analyzed and discussed.

\section{Modeling of the Cladding Damping Structure}

Many previous researchers have reported that metal rubber is a nonlinear material. Its dynamic model includes a memory link and a nonmemory link characterized by the change of damping and stiffness during the vibration damping process. Based on the bilinear hysteresis model [3], the mechanical model of the single degree of freedom hysteresis system can be made linearly equivalent by using the equivalent linearization method involved in the change law of stiffness and damping of metal rubber.

2.1. Dynamic Analysis. The cladding damping structure includes the metal rubber, the pipeline, and the cladding ring. The metal rubber is coated on the outside of the pipe through the cladding ring as the damping layer. The structure is composed of the damping layer and hanger and can be regarded as the shock absorber of the pipeline system. The scheme of metal rubber coating and its damping structure can be seen in Figure 1.

The pipe is subjected to radial force $F$ when the pipe moves up and down and the direction of the force on the top is down; meanwhile, force on the bottom is opposite to this. Other forces can be decomposed into vertical forces $F_{2}$ and horizontal forces $F_{1}$. The direction of vertical forces on both sides of the pipe is the same, and the horizontal forces are opposite, so the horizontal forces can counteract each other. In this case, the pipeline can be regarded as vertical force, and the pipeline in the cladding damping structure can be regarded as a lumped mass.

There is a $5 \mathrm{~mm}$ gap between the two cladding rings, which is used to adjust the pretightening force. The damping layers can always closely contact both the pipe and the cladding rings because of the pretightening force, so the metal rubber layers are always in a state of force. The metal rubber layers can be seen to be closely contacting each other at all times, so there is no relative slip between the metal rubber layers. Furthermore, it can be estimated that there is no energy dissipation within the metal rubber layers.

The forces of the upper and lower damping layers are unequal due to the gravity of the pipeline, and the forces of

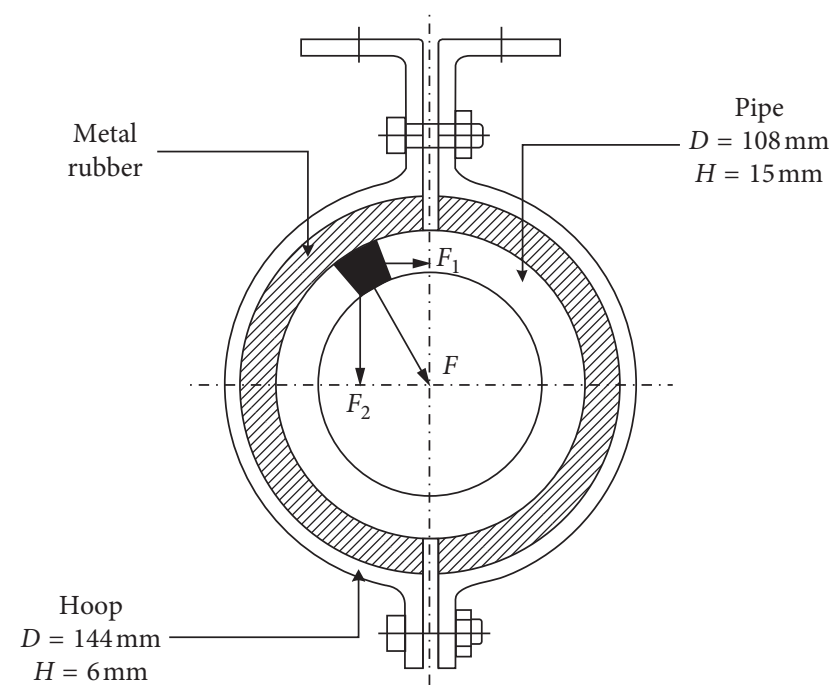

Figure 1: Scheme of the metal rubber coating.

the lower layers are greater than those of the upper layers. The pipe will vibrate up and down when it is affected by the external incentive. In this case, the stiffness of the whole damping coating structure can be regarded as $K$ and the damping as $C$, and the nonlinear part of the cladding damping structure can be expressed by the memory link $Z(t)$. Based on this, the cladding damping structure can be further simplified as a bilinear hysteretic oscillator model with viscous damping, and its dynamic model is established, as shown in Figure 2.

In Figure 2, $F_{\mathrm{e}}$ is the external incentive, which is $F_{\mathrm{e}}=P_{0} \sin \omega t . K$ is the stiffness of the cladding damping structure, $Z_{\mathrm{s}}$ is the restoring force of slip, and $K_{\mathrm{s}}$ is the linear stiffness before slip.

On the basis of Newton's second law, the differential equation of motion of the cladding damping structure is established as follows:

$$
M \ddot{X}+C \dot{X}+K X+Z(t)=P_{0} \sin \omega t
$$

Substituting the variables:

$$
\begin{aligned}
2 \xi & =\frac{C}{M}, \\
\omega_{0}^{2} & =\frac{K}{M}, \\
P & =\frac{P_{0}}{M} .
\end{aligned}
$$

From Equations (1) and (2), the differential equation of motion can be given by

$$
\ddot{X}+2 \xi \dot{X}+\omega_{0}^{2} X+\frac{1}{M} Z(t)=P \sin \omega t .
$$

2.2. Variable Stiffness and Damping Characteristics. A large number of previous experiments [14] prove that the highorder harmonics contained in the hysteretic oscillator response can be neglected, and the fundamental component is 


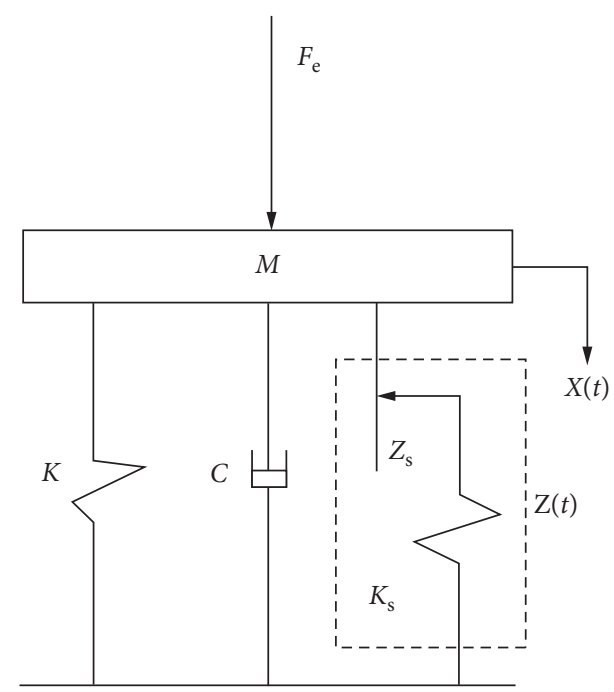

Figure 2: Dynamic model of the cladding damping structure.

dominant, so we assume the applied displacement excitation is

$$
X=X_{\mathrm{m}} \sin (\omega t+\phi) .
$$

The memory link model is shown in Figure 3(a), and its equivalent linear model related to the linear viscous damping and spring parallel structure is shown in Figure 3(b).

In Figure 3, the equivalent viscosity damping coefficient and stiffness coefficient can be shown as $C_{\mathrm{eq}}$ and $K_{\mathrm{eq}}$ in equivalent links, so the memory link $Z(t)$ can be given by

$$
Z(X, \dot{X})=C_{\mathrm{eq}} \dot{X}+K_{\mathrm{eq}} X .
$$
is

The derivative of displacement excitation (Equation (4))

$$
\dot{X}=X_{\mathrm{m}} \omega \cos (\omega t+\varphi) \text {. }
$$

From Equations (5) and (6), the memory link can be expressed by

$$
Z(X, \dot{X})=C_{\mathrm{eq}} X_{\mathrm{m}} \omega \cos (\omega t+\varphi)+K_{\mathrm{eq}} X_{\mathrm{m}} \sin (\omega t+\varphi) .
$$

The coordinate transformation is given as follows:

$$
\begin{aligned}
\tau & =t-t_{\mathrm{s}}, \\
t_{\mathrm{s}} & =\left(\frac{\pi}{2}-\varphi\right) \frac{1}{\omega} .
\end{aligned}
$$

A simplification of Equation (7) is made, and after the averaging operation, the displacement excitation can be shown as follows:

$$
X=X_{\mathrm{m}} \sin (\omega t+\varphi)=X_{\mathrm{m}} \cos \omega \tau=X_{\mathrm{m}} \cos \theta .
$$

From the bilinear hysteresis model $[3,15]$, the memory link $Z(t)$ can be divided into

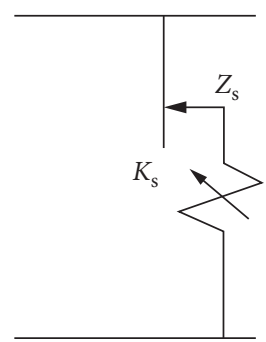

(a)

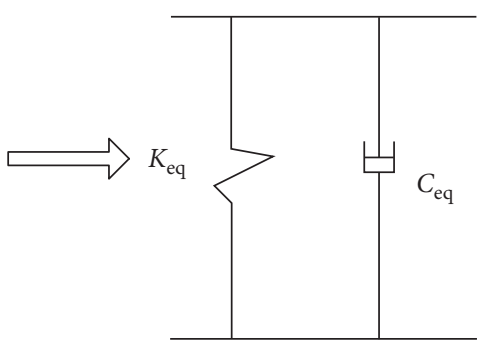

(b)
FIgURE 3: (a) The memory link model and (b) its equivalent linear model.

$$
Z(\theta)= \begin{cases}K_{\mathrm{s}}\left(X-X_{\mathrm{m}}\right)+Z_{\mathrm{s}}, & 0<\theta<\theta^{*}, \\ -Z_{\mathrm{s}}, & \theta^{*}<\theta<\pi, \\ K_{\mathrm{s}}\left(X+X_{\mathrm{m}}\right)-Z_{\mathrm{s}}, & \pi<\theta<\pi+\theta^{*}, \\ Z_{\mathrm{s}}, & \pi+\theta^{*}<\theta<2 \pi .\end{cases}
$$

In Equation (10):

$$
\theta^{*}=\arccos \left(1-\frac{2 X_{\mathrm{s}}}{X_{\mathrm{m}}}\right)
$$

Furthermore, Equations (12) and (13) can be obtained after simplifying, integrating, and collating as follows:

$$
\begin{aligned}
& C_{\text {eq }}=\frac{4 Z_{\mathrm{s}}}{\pi \omega X_{\mathrm{m}}}\left(1-\frac{X_{\mathrm{s}}}{X_{\mathrm{m}}}\right), \\
& K_{\text {eq }}=\frac{K_{\mathrm{s}}}{\pi}\left(\theta^{*}-\sin \theta^{*} \cos \theta^{*}\right) .
\end{aligned}
$$

Assuming that

$$
\begin{aligned}
& n_{\mathrm{c}}=\frac{\pi \omega X_{\mathrm{m}}}{4 Z_{\mathrm{s}}} C_{\mathrm{eq}}, \\
& n_{\mathrm{k}}=\frac{\pi}{k_{\mathrm{s}}} K_{\mathrm{eq}} .
\end{aligned}
$$

Parameter $n_{\mathrm{c}}$ and $n_{\mathrm{k}}$ curves with $X_{\mathrm{m}} / X_{\mathrm{s}}$ were drawn and delineated, as shown in Figures 4(a) and 4(b), respectively.

It can be seen from Figure 4(a) that the equivalent viscous damping coefficient $C_{\mathrm{eq}}$ from $0 \longrightarrow\left(\left(4 Z_{\mathrm{s}}\right) /\right.$ $\left.\left(\pi \omega X_{\mathrm{m}}\right)\right)$, when $\left(X_{\mathrm{m}} / X_{\mathrm{s}}\right) \longrightarrow \infty, n_{\mathrm{c}}=\left(\left(\pi \omega X_{\mathrm{m}}\right) /\left(4 Z_{\mathrm{s}}\right)\right)$ $C_{\mathrm{eq}} \longrightarrow 1$, and the equivalent stiffness $K_{\mathrm{eq}}$ from $k_{\mathrm{s}} \longrightarrow 0$, when $\left(X_{\mathrm{m}} / X_{\mathrm{s}}\right) \longrightarrow \infty, n_{\mathrm{k}}=\left(\pi / k_{\mathrm{s}}\right) K_{\text {eq }} \longrightarrow 0$. This indicates that with the increase of excitation displacement, the damping property of metal rubber is enhanced and the stiffness characteristic of metal rubber is decreased.

\section{Performance Characterization of the Cladding Damping Structure}

In the cladding damping structure, metal rubber is mainly converted into thermal energy through kinetic energy to achieve energy consumption. The energy dissipation characteristics of the cladding damping structure are characterized by the force transfer rate and the structural loss factor. 


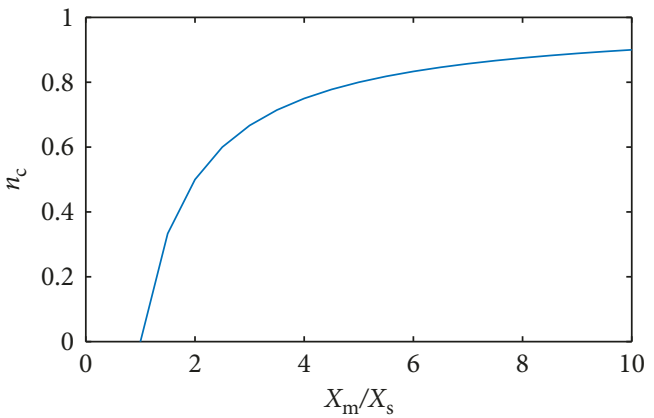

(a)

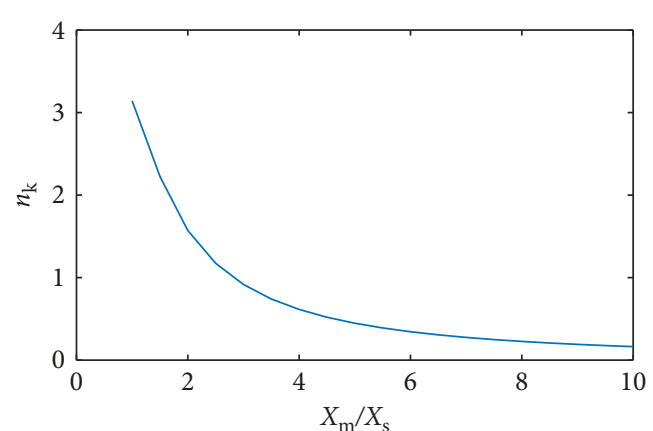

(b)

Figure 4: (a) Parameter $n_{\mathrm{c}}$ curve with $X_{\mathrm{m}} / X_{\mathrm{s}}$; (b) parameter $n_{\mathrm{k}}$ curve with $X_{\mathrm{m}} / X_{\mathrm{s}}$.

3.1. The Force Transfer Rate. The force transfer rate is the earliest evaluation index of the vibration isolation effect, which is defined as the ratio of excitation force to responsive force. The responsive force is the force that the excitation force transmits to the foundation [16]. In the cladding damping structure, the excitation force applied to the pipe is defined as $F$, the responsive force is $\widetilde{F}$, and the system force transfer rate $T_{\mathrm{A}}$ can be expressed as:

$$
T_{\mathrm{A}}=\frac{\widetilde{F}}{F}
$$

The transfer rate is based on the assumption of a rigid foundation and is only applicable to low frequency bands. The cladding damping structure of the pipeline coating system is the vibration isolation system, and it is based on the support of a rigid foundation. The assumption stands if the sweep frequency interval is set in the low frequency range. The energy dissipation characteristics of metal rubber can be qualitatively characterized according to the force transfer rate $T_{\mathrm{A}}$.

3.2. The Structural Loss Factor. The frequency-response curves of the pipeline system can be obtained through experiments, and the structural loss factor of the cladding damping structure can be calculated by using the half-power method. The half-power method is the most commonly used method to obtain damping values in the frequency domain. The dynamic flexibility curve (the ratio of dynamic displacement to excitation force), the admittance curve (ratio of velocity to excitation force), and inertial rate curve (ratio of acceleration to excitation force) can be used as the frequency-response curves [17-19]. In this paper, according to the inertial rate curve shown in Figure 5, taking the frequencies $\omega_{1}$ and $\omega_{2}$ corresponding to $(1 / \sqrt{2})|H|_{\max }$ value, the loss factor of the cladding damping structure can be obtained by the following equation:

$$
\eta=\frac{\Delta \omega}{\omega_{\mathrm{n}}}=\frac{\omega_{2}-\omega_{1}}{\omega_{\mathrm{n}}} .
$$

\section{Specimen Preparation and Preparation of the Test Bench}

4.1. Specimen Preparation. The preparation process of the metal rubber specimens for the experiment is shown in

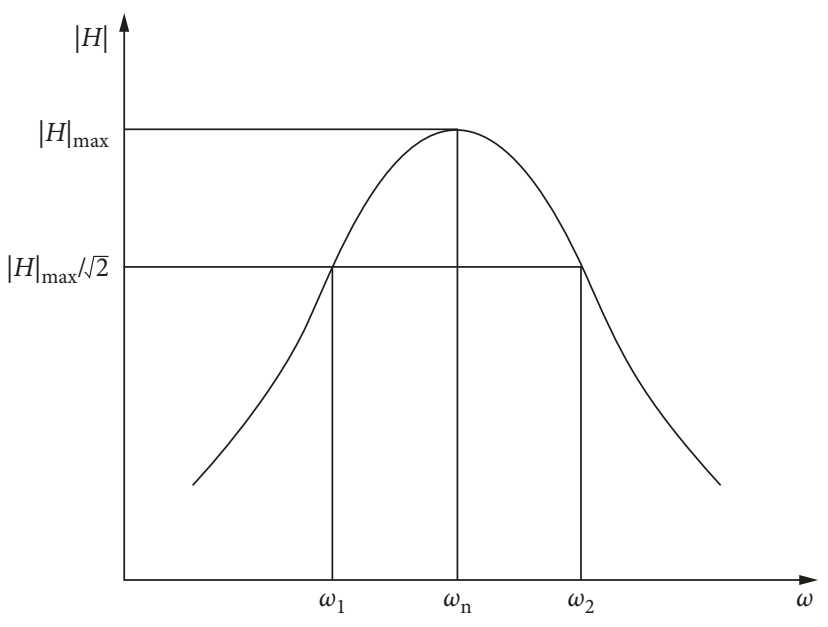

FIgURE 5: The inertia rate curve.

Figure 6, including wire winding, stripping, and stamping. The raw material of the specimen is austenitic stainless steel wire [20], because the ductility is very high in a hightemperature environment, so it can withstand coating the pipeline in such a high-temperature environment.

The metal rubbers need to meet special application requirements. The difficulties of preparation include the preparation of the blank from a thin sheet of metal rubber, especially the selection of the core-shaft winding method to make the blank. The wires should have a perfect connection between each layer of the spiral coil and the next layer after drawing to avoid a pitch that is too large or too small, which can be caused by an incomplete or loose connection, among other problems. After the spiral coil was wound, the blank was removed from the core axis and placed in the mold. The top and bottom layers of the spiral coil will be hooked together after compression and, because the center of the blank is hollow, the sheet metal rubber specimen can be obtained by cold stamping. Problems with the sheet metal rubber specimen are that the edge angle is not full, and the thickness is inconsistent. The solution to these kinds of problems can be addressed in the following ways:

(1) The winding length of the blank should be greater than the length of the specimen. Because the blank 


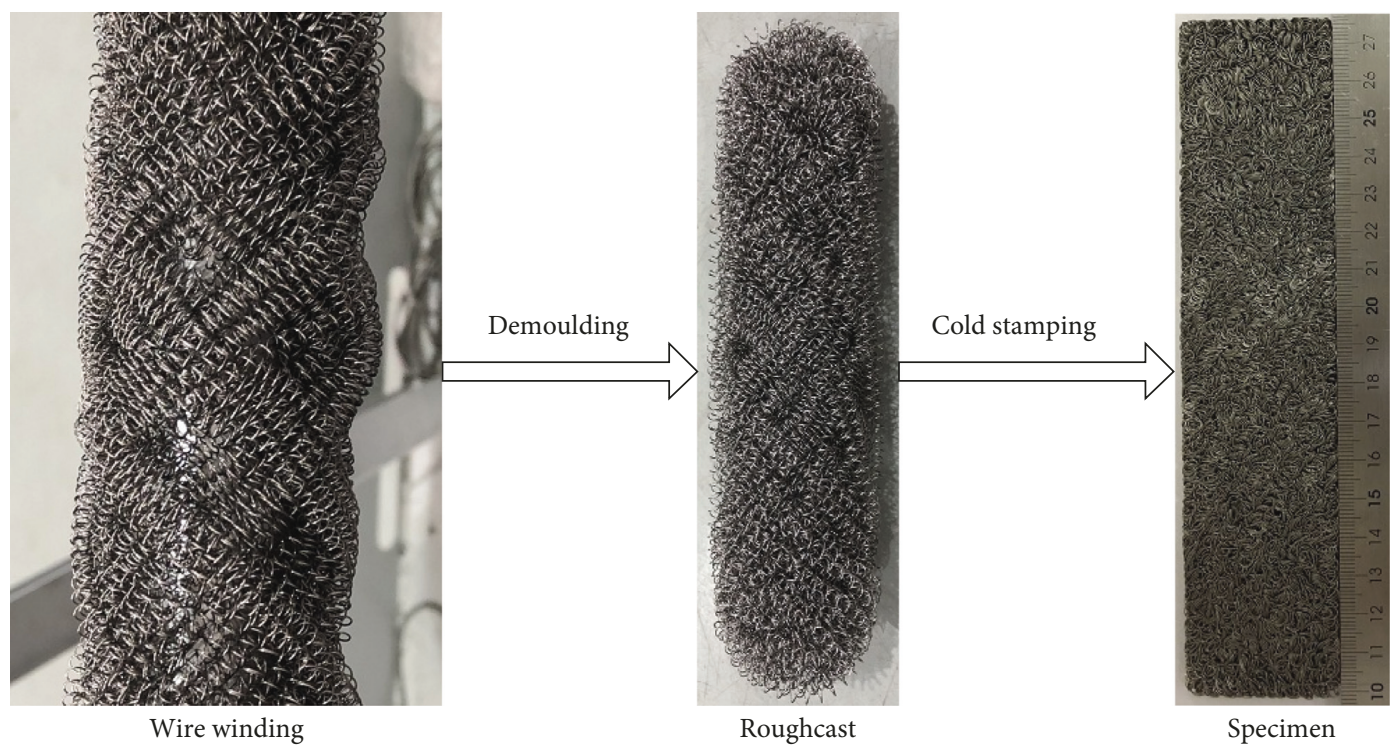

FIgURE 6: The preparation of metal rubber specimens.

will shrink after it is removed from the core axis, the shrinkage should be made up to meet the requirement of the length of the specimen.

(2) The amount of wire is not uniform, because of the intersecting edges of the blank, so it is necessary to supplement the wire manually to meet the quality of the edge.

(3) The cross angle of spiral winding should be large enough, as the problem of looseness is caused by an insufficient winding angle.

(4) The thickness of the blank should be uniform, especially the end part of the blank. The thickness of the end part should be a little larger than that of the middle part, so as to avoid the imbalance of pressure between both ends caused by the thickness of the blank.

The raw material of the specimen is $06 \mathrm{Cr} 19 \mathrm{Ni10}$ stainless steel wire, with a wire diameter of $\varphi 0.3 \mathrm{~mm}$. The stainless steel wire is processed into a spiral coil by a wire winding machine, and the spring diameter is controlled at $3 \mathrm{~mm}$ by adjusting the probe position and stretching quantity of the wire winding machine. The metal wire is installed into the blank winding machine after ensuring that the exact quality of the wire, the spindle speed, and the wire feeding speed are cooperating well. The forming spiral winding pitch is twined on the core shaft after drawing. The winding angle of the blank is 60 degrees, and the uniformity of the pitch can be guaranteed by the machine drawing the pitch to ensure the consistency of the forming process of the specimen. The blank is placed in the designed mold shown in Figure 7, after the blank winding is completed. The mold includes the external mold, press mold, internal mold, and metal rubber roughcast.

By utilizing the $1000 \mathrm{kN}$ cold stamping machine, which is produced by the Tianjin Huidian Company and used in the cold stamping process, the stamping uniformity should be guaranteed when punching. Firstly, pressing to the set pressure, then adding the pressure to the set pressure for $30 \mathrm{~s}$, and then releasing the pressure was carried out, and the process was repeated three times. The metal wire in the blank was completed to ensure a better performance of the metal rubber parts. The size of the metal rubber specimen is $175 \mathrm{~mm} \times 40 \mathrm{~mm} \times 4 \mathrm{~mm}$, and the technological parameters are listed in Table 1 .

4.2. Test Bench. On the basis of the existing experimental conditions, the pipe parameters were the external diameter of the pipe $(D=108 \mathrm{~mm})$, the thickness of the pipe $(H=$ $15 \mathrm{~mm})$, and the length of the pipe $(L=5600 \mathrm{~mm})$. The material of the pipe was 304 stainless steel, and the corresponding hanger and experimental stand were designed based on these measurements. The construction of the test bench is exhibited in Figure 8(a).

The cladding damping structure (Figure 8(b)), fixed on the support, was formed by the pipelines, the hangers, and the dampers. The support was fixed on the support platform by T-type bolts. The support platform can be considered as a clamping platform, as it is a solid steel platform of better quality than the support and the pipeline system. There were two force sensors installed between the supports and the hangers to measure the response of the vibration from the pipe to the support. The vibration exciter was suspended above the center of the pipe by a crane hook and a rubber rope, and the exciting force was applied to the midpoint of the pipe. An acceleration sensor was installed directly below the exciting point of the pipeline to measure the response acceleration. The connecting rod of the exciter was equipped with a force sensor to measure the fundamental excitation force, and the measurement data were transmitted to the vibration control system and the computer. The test flow chart is displayed in Figure 8(c).

The E-JZK-50 type electric vibrator produced by Hangzhou Yiheng Science and Technology Co., Ltd., was 


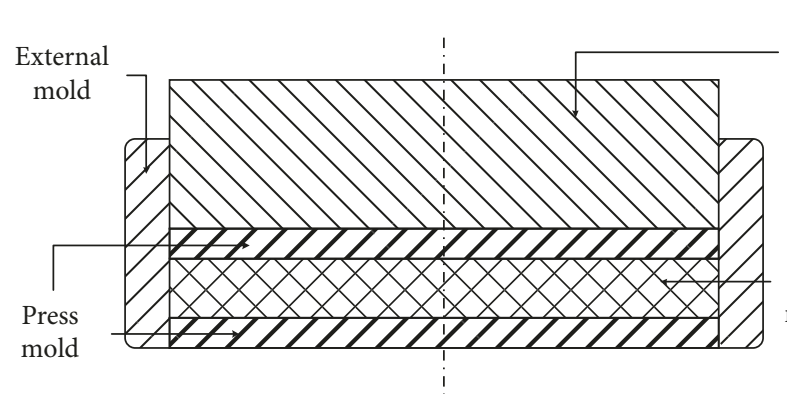

(a)

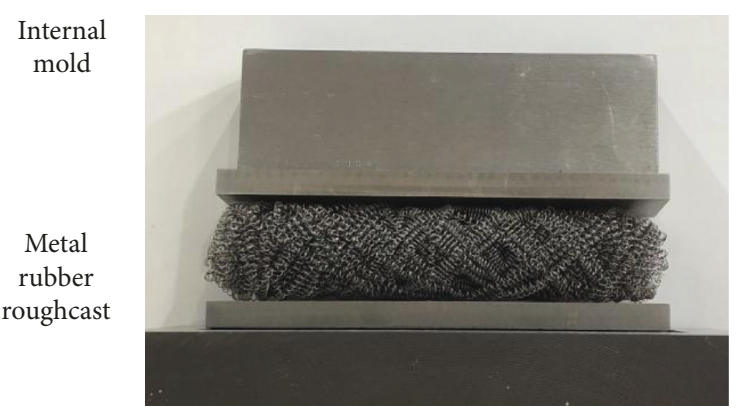

(b)

FIgURE 7: The metal rubber mold.

Table 1: Process parameters for the metal rubber specimens.

\begin{tabular}{lccc}
\hline Number & Mass $(\mathrm{g})$ & Pressure $\left(\mathrm{kN} / \mathrm{cm}^{2}\right)$ & Density $\left(\mathrm{g} / \mathrm{cm}^{3}\right)$ \\
\hline 1 & 60 & 5.71 & 2.143 \\
2 & 70 & 8.57 & 2.5 \\
3 & 80 & 14.29 & 2.857 \\
\hline
\end{tabular}

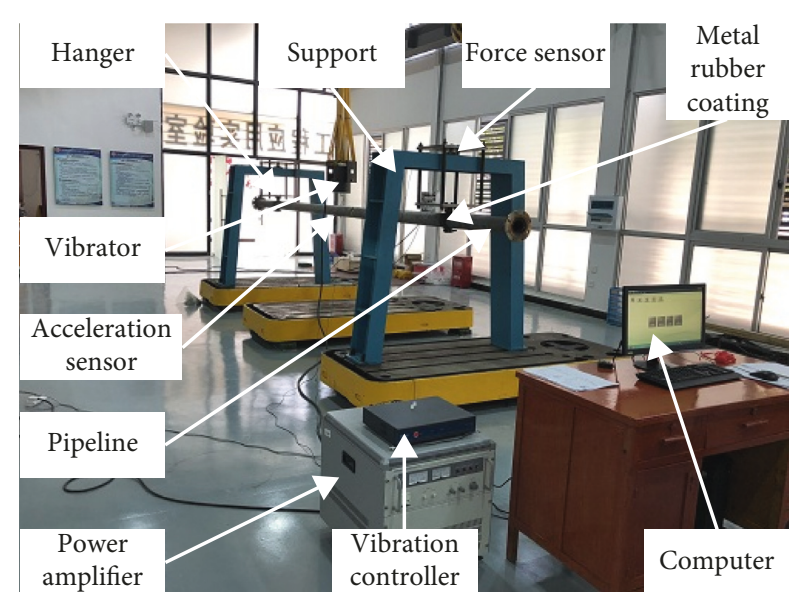

(a)

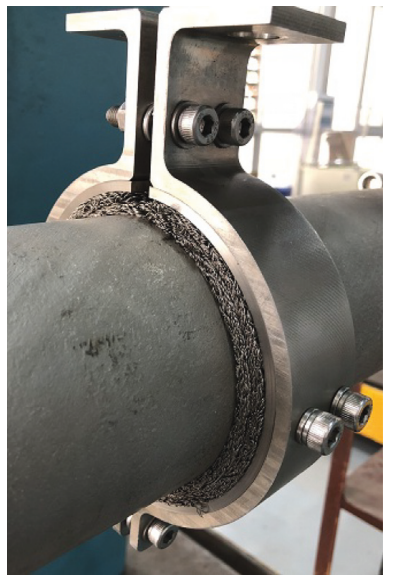

(b)

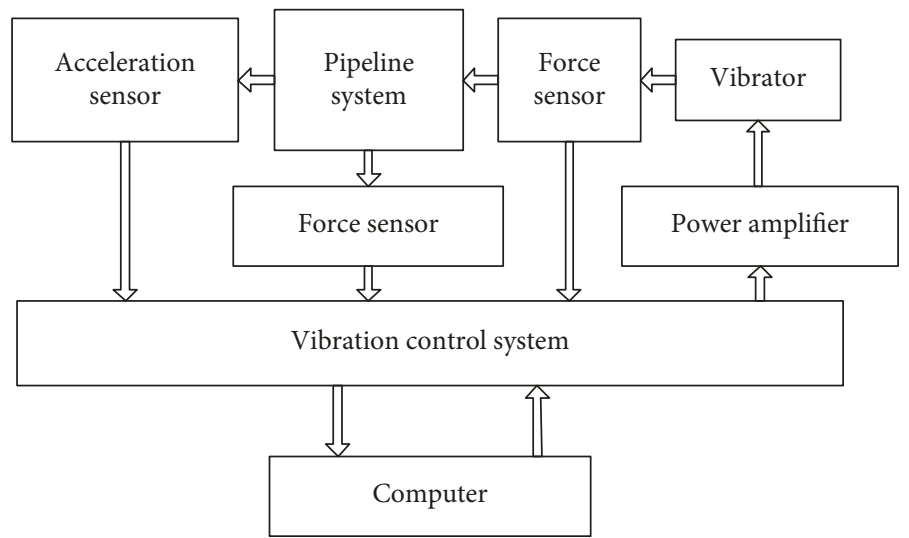

(c)

Figure 8: (a) Test bench; (b) coated damping structure; (c) test flow chart. 
used to test the testing equipment. The maximum exciting force was $500 \mathrm{~N}$, the maximum amplitude was $\pm 10 \mathrm{~mm}$, the maximum acceleration was $49.5 \mathrm{~g}$, and the frequency range was DC-2 kHz. The E5874A power amplifier was used with the exciter. A YD-303 piezoelectric quartz force sensor with a charge sensitivity of $3.00 \mathrm{pC} / \mathrm{N}$ was used between the connecting rod and the exciter; its working temperature region was -40 to $150^{\circ} \mathrm{C}$, and the measuring range of force was $\pm 2 \mathrm{kN}$. The model of the KD3000 quartz force sensor with a charge sensitivity of $3.408 \mathrm{pC} / \mathrm{N}$ was used at the response point of the support; its working temperature region was -40 to $200^{\circ} \mathrm{C}$, and the measuring range of force was $0-5 \mathrm{kN}$. A $1 \mathrm{~A} 102 \mathrm{E}$ type IEPE piezoelectric accelerometer was used at the response point of the pipeline; its sensitivity was $10.80 \mathrm{MV} / \mathrm{g}$, and the measuring range was $\pm 500 \mathrm{~g}$.

\section{Results and Analysis}

First of all, a sinusoidal sweep frequency excitation of $20 \mathrm{~N}$ was carried out for a rigid pipe system, and the sweep frequency range was $5-200 \mathrm{~Hz}$. Figure 9 shows the force transfer rate curve of the rigid pipeline system. The selected frequency range is dependent on the peak numbers of the force transfer rate $\left(T_{\mathrm{A}}\right)$ by experimental test. Generally, the first three natural frequencies are enough for the analyses of force transfer rate evolution. In this study, the experimental test results have already three peak numbers of the force transfer rate under the testing frequency range from $5 \mathrm{~Hz}$ to $200 \mathrm{~Hz}$. As the authors wrote in the paper, the natural frequency is mainly used for comparison, like "low-order frequency" and "high-order frequency." In fact, it would be too many external noises (e.g., electromagnetic interference) to identify the force transfer rate when the frequency was higher than $200 \mathrm{~Hz}$. Therefore, the authors only chose the frequency range from $5 \mathrm{~Hz}$ to $200 \mathrm{~Hz}$ for the analysis.

From the force transfer rate curve, it is obvious that the first-order natural frequency has the greatest influence on the vibration of the pipeline system. A great deal of research experience shows that the system vibration has the greatest influence on low-order natural frequencies. This is because the frequency of the general load is lower than that of the actual engineering vibration, and the resonance of the pipeline is often caused by a low-order natural frequency. The high-order resonance energy is relatively low, and the influence on the structure is much smaller than that of the low-order resonance. Therefore, only the vibration at the first-order natural frequency point can be considered, and the vibration at the first-order natural frequency can be considered as the object of study. In order to study the vibration of the pipeline system in a convenient way, the sweep frequency range was set to $10-20 \mathrm{~Hz}$. The frequency sweep rate was $1 \mathrm{OCT} / \mathrm{min}$.

5.1. Study of Stiffness and Damping Characteristics. Before the experiment, the suspension height of the exciter was adjusted to give the exciter an appropriate pretightening force, so as to prevent the shock exciter from breaking away

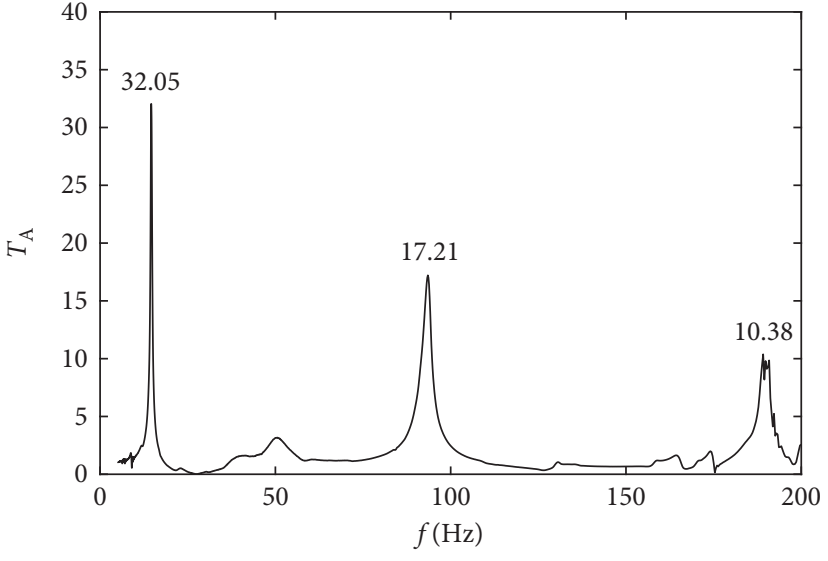

FIgURE 9: The force transfer rate curve of the pipeline.

from the pipe due to the exciting force. The accuracy of the experiment will be affected by this. The experiment conditions should remain unchanged after adjusting the pretightening force. The different densities (specimen 1, specimen 2 , and specimen 3 ) and the number of different cladding layers (one layer, two layers, and three layers) were applied to different exciting forces of different magnitudes $(20 \mathrm{~N}, 50 \mathrm{~N}$, and $80 \mathrm{~N})$, and the experiment process for different parameters must ensure the consistency of other conditions in order to achieve standardization of the test.

According to the data obtained from the force transfer rate experiment of specimen 2 under different excitatory magnitudes $(20 \mathrm{~N}, 50 \mathrm{~N}$, and $80 \mathrm{~N})$, the curves of the force transfer rate frequency are drawn (Figure 10). The other conditions of different exciting magnitudes are the same, and the number of coating layers is two.

According to the experimental data, the natural frequency and the peak values of the force transfer rate under different excitations are obtained, as listed in Table 2.

As can be seen from Figure 10 and Table 2, with the increase of the magnitude of excitation, the natural frequency $\omega_{\mathrm{n}}$ tends to decrease and the peak value of the force transfer decreases notably. Because the increase of the magnitude of excitation leads to the increase of displacement, the metal rubber produces a stiffness softening and damping energy dissipation enhancement effect. The experimental results agree with the theoretical analysis (Figure 4), which proves the rationality and accuracy of the theoretical analysis.

\subsection{Damping Characteristics}

5.2.1. Different Densities. According to the experimental data of different specimens (specimen 1, specimen 2, and specimen 3), under the conditions of $50 \mathrm{~N}$ excitation and two layers of cladding, the force transfer rate frequency curves and the inertia rate frequency curves are drawn (Figures 11(a) and 11(b)).

According to the computing method (Equation (15)) of the force transfer rate, the peak of the force transfer rate $T_{\mathrm{Am}}$ of different specimens is obtained, and the structural loss 


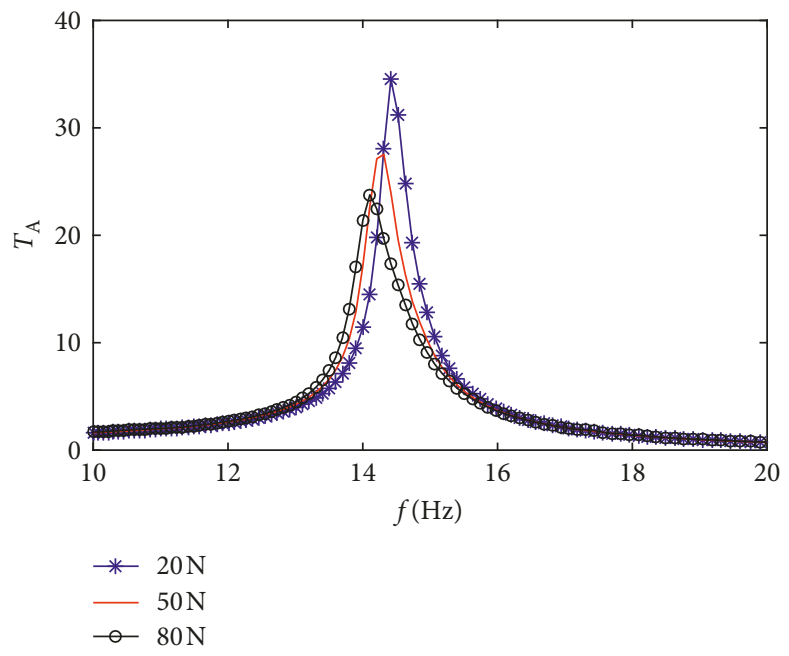

Figure 10: The force transfer rate frequency curves of different vibration magnitudes.

TABLE 2: Natural frequencies and the peak values of the force transfer rate under different excitation levels.

\begin{tabular}{lccc}
\hline Exciting magnitude & $20 \mathrm{~N}$ & $50 \mathrm{~N}$ & $80 \mathrm{~N}$ \\
\hline Natural frequency $\omega_{\mathrm{n}}(\mathrm{Hz})$ & 14.418 & 14.271 & 14.084 \\
Peak of the force transfer rate $T_{\mathrm{Am}}$ & 34.522 & 28.332 & 23.782 \\
\hline
\end{tabular}

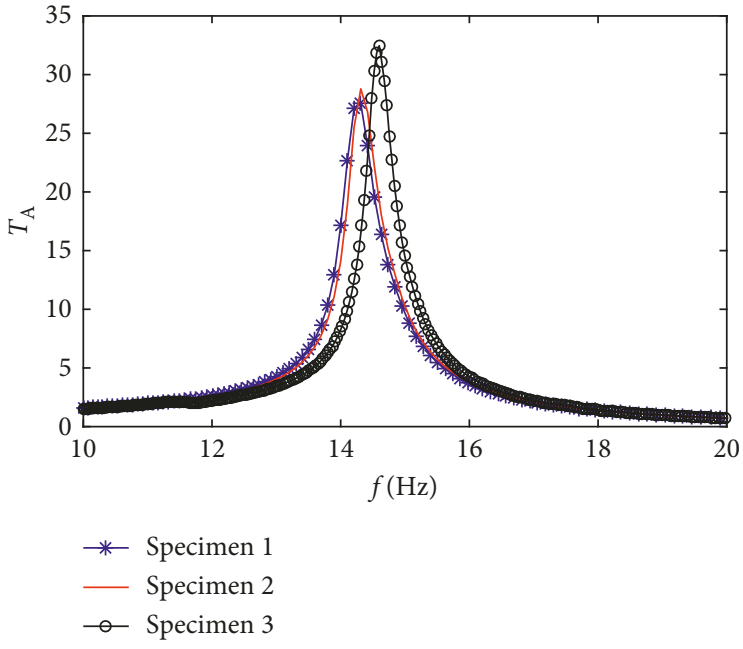

(a)

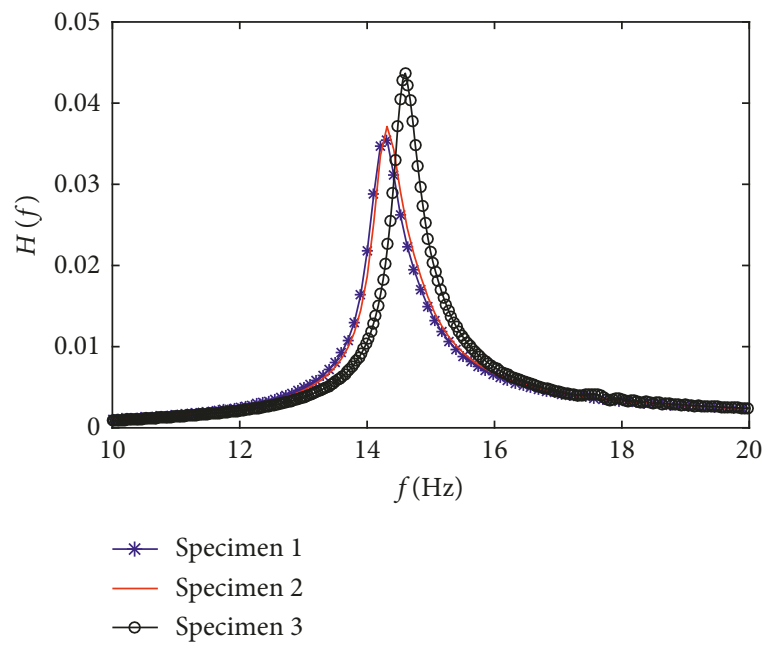

(b)

Figure 11: (a) The force transfer rate frequency curves at different densities; (b) the inertia rate frequency curves under different densities.

factor $\eta$ is calculated based on the half-power method, as shown in Table 3.

From Figure 11 and Table 3, it can be seen that with the increase of specimen density, the peak of the force transfer rate $T_{\mathrm{Am}}$ of the cladding damping structure increases and the structural loss factor $\eta$ decreases. With the increase of the density of metal rubber, the number of wires inside increases and the number of contact points between wires will increase accordingly. The ability of metal rubber to overcome the external load will be enhanced as the stiffness of the metal rubber increases. Under the condition of constant excitation on the order of $50 \mathrm{~N}$, the stiffness increases and the amplitude decreases with the increase of the density of the metal rubber specimen. The energy consumption and the potential energy of the metal rubber decrease because of the increase of the stiffness and the increase of the metal wire inside the metal rubber. The force transfer rate increases and the structural loss factor decreases with the increase of the density of metal rubber, according to the formula of the loss factor [21]. 
TABLE 3: Vibration absorption characteristics at different densities.

\begin{tabular}{lccc}
\hline Density & Specimen 1 & Specimen 2 & Specimen 3 \\
\hline Peak of the force transfer rate $T_{\text {Am }}$ & 28.332 & 28.786 & 32.456 \\
Structural loss factor $\eta$ & 0.0343 & 0.0334 & 0.0269 \\
\hline
\end{tabular}

5.2.2. Different Excitation Magnitudes. The force transfer rate frequency curves and the inertia rate frequency curves are drawn, as can be seen in Figures 10 and 12, according to the experimental data measured from specimen 1 under the conditions of different excitatory magnitudes $(20 \mathrm{~N}, 50 \mathrm{~N}$, and $80 \mathrm{~N}$ ) and two layers of cladding.

The peak value of the force transfer rate $T_{\mathrm{Am}}$ of different excitatory magnitudes is obtained according to the computing method (Equation (15)) of the force transfer rate. The structural loss factor $\eta$ is calculated based on the half-power method, as presented in Table 4.

From Figures 10 and 12 and Table 4, it can be seen that the peak force transfer rate $T_{\mathrm{Am}}$ of the cladding damping structure tends to decrease, and the structural loss factor $\eta$ increases gradually with the increase of the exciting magnitude. The amplitude response increases with the increase of the exciting magnitude, the slip amplitude between metal wires increases with the increase of amplitude, and the energy dissipation characteristic increases accordingly under the conditions of a certain density of metal rubber. This is because metal rubber energy dissipation is achieved by sliding dry friction between wires. The experimental results show that the force transfer rate decreases and the structural loss factor increases. The energy dissipation characteristics of metal rubber are enhanced with the decrease of the force transfer rate and the increase of the structural loss factor. The magnitude of excitation increases from $20 \mathrm{~N}$ to $80 \mathrm{~N}$ and the span is $30 \mathrm{~N}$, and the force transfer rate clearly decreases. This shows that the magnitude of excitation has a great influence on the energy dissipation characteristics. Furthermore, the structural loss factor can quantitatively describe the energy dissipation enhancement characteristics of metal rubber.

5.2.3. Different Cladding Layers. According to the experimental data measured from specimen 1 , the force transfer rate frequency curves and the inertia rate frequency curves are drawn, as shown in Figures 13(a) and 13(b), under the conditions of different cladding layers (one layer, two layers, and three layers) and an exciting magnitude of $50 \mathrm{~N}$.

The peak value of the force transfer rate $T_{\mathrm{Am}}$ of different excitatory magnitudes is obtained according to the computing method (Equation (15)) of the force transfer rate. The structural loss factor $\eta$ is calculated based on the half-power method, as demonstrated in Table 5.

From Figure 13 and Table 5, it can be seen that the peak of the force transfer rate, $T_{\mathrm{Am}}$, of the cladding damping structure tends to decrease and the structural loss factor $\eta$ increases gradually with the increase of cladding layers. The stiffness of the metal rubber decreases with the increase of the number of cladding layers, according to Hooke's law. This is manifested in the decrease of natural frequency,

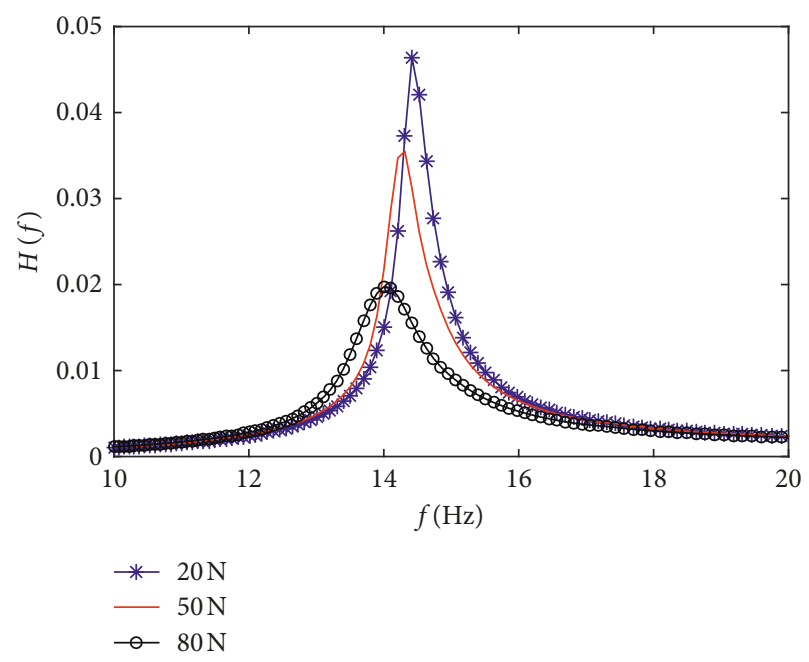

FIGURE 12: The inertia rate frequency curves at different excitation levels.

TABLE 4: Characteristics of vibration reduction under different magnitudes of excitation.

\begin{tabular}{lccc}
\hline Exciting magnitudes & $20 \mathrm{~N}$ & $50 \mathrm{~N}$ & $80 \mathrm{~N}$ \\
\hline Peak of the force transfer rate $T_{\mathrm{Am}}$ & 34.522 & 28.332 & 23.782 \\
Structural loss factor $\eta$ & 0.0260 & 0.0343 & 0.0644 \\
\hline
\end{tabular}

which can be confirmed from Figure 13. In addition, the damping increases with the increase of the number of cladding layers, which is because of the decrease of metal rubber stiffness with the increase of layers. As the number of cladding layers increases, the slip amplitude inside metal rubber will increase, which will lead to increased energy consumption. On the other hand, the number of wires and the friction of the contact point are increased with the increase of the number of layers, which undoubtedly enhances the energy dissipation characteristics.

\section{Conclusions}

(1) In this paper, the mechanical behavior of the metal rubber cladding damping structure was analyzed, and the dynamic model was established. The variable stiffness and variable damping characteristics of the metal rubber were obtained by using the equivalent linearization method. The results reveal that the stiffness of metal rubber softens, and the damping of metal rubber is enhanced, with the increase of the loading amplitude. The rationality and accuracy of the analysis are verified by experiments. 


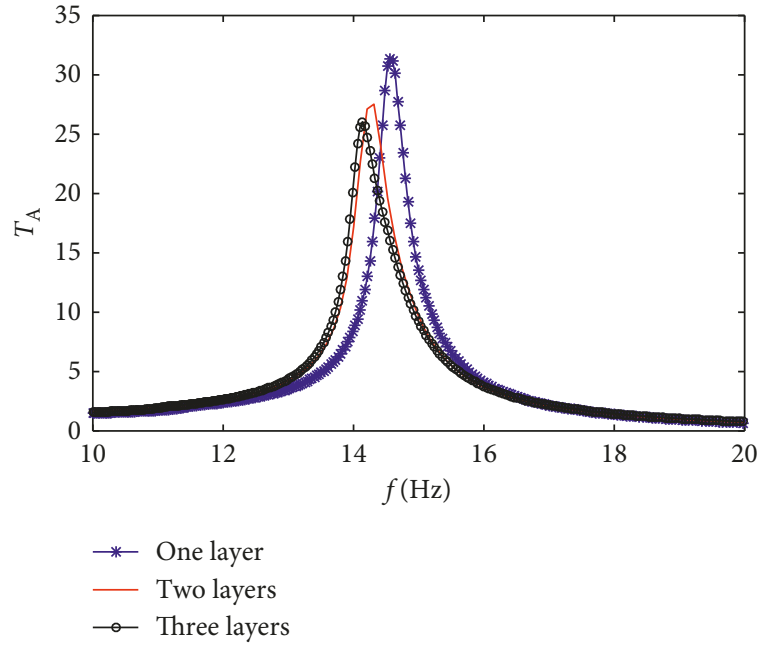

(a)

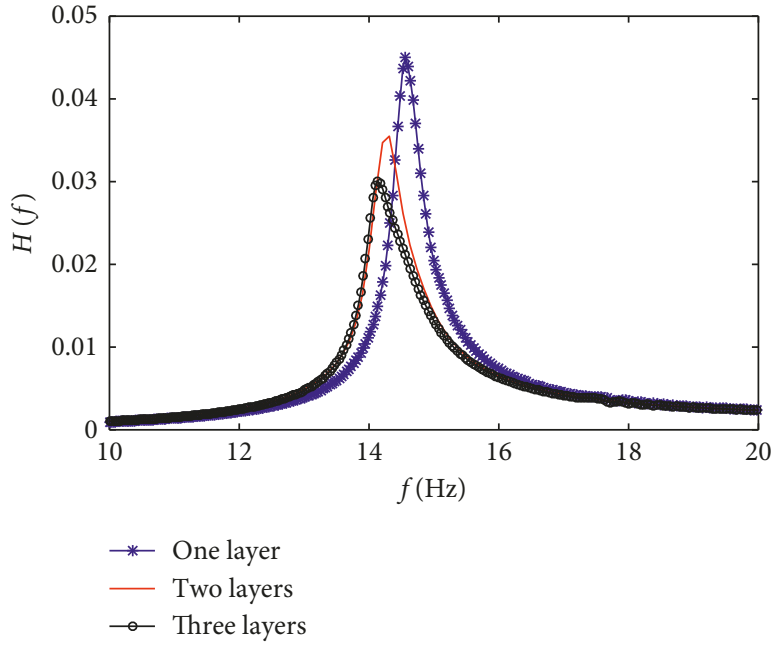

(b)

Figure 13: (a) The force transfer rate frequency curves with different cladding layers; (b) the inertia rate frequency curves with different cladding layers.

TABLE 5: Vibration absorption characteristics with different cladding layers.

\begin{tabular}{lccc}
\hline Cladding layer & One layer & Two layers & Three layers \\
\hline $\begin{array}{l}\text { Peak of the force transfer } \\
\text { rate } T_{\text {Am }}\end{array}$ & 31.668 & 28.332 & 26.052 \\
Structural loss factor $\eta$ & 0.02674 & 0.03433 & 0.04193 \\
\hline
\end{tabular}

(2) The force transfer rate and the structural loss factor were proposed to characterize the damping performance of the cladding damping structure. The variation of damping performance with density, the number of cladding layers, and the magnitude of excitation were studied experimentally. The results showed that the damping property of metal rubber increased with the increase of the number of cladding layers and the magnitude of excitation, and the energy dissipation characteristic of metal rubber decreased with the increase of density under the same exciting magnitude.

The research in this paper provides a theoretical and experimental basis for the study of the vibration reduction of pipeline systems in engineering and has a clear guiding significance for future research work on the vibration damping of high-temperature pipeline systems.

\section{Data Availability}

The data used to support the findings of this study are included within the article.

\section{Conflicts of Interest}

The authors declare that they have no conflicts of interest regarding the publication of this article.

\section{Acknowledgments}

The authors wish to thank all the members of Engineering Research Center for Metal Rubber in Fuzhou University for the assistance of all the experimental tests. This project was supported by Weapon Equipment "Thirteenth Five-Year Plan" Advance Research Project of China (99502040604), National Natural Science Foundation of China (no. 51705080), Natural Science Foundation of Fujian Province (no. 2018J01764), and Fuzhou Science and Technology Project (2016-G-67).

\section{References}

[1] G. Mikota, B. Manhartsgruber, H. Kogler, and F. Hammerle, "Modal testing of hydraulic pipeline systems," Journal of Sound and Vibration, vol. 409, no. 24, pp. 256-273, 2017.

[2] S. Q. Liang, J. L. Chen, Y. Hu, and G. X. Pan, "Research on vibration control of ship pipeline system, Ship Science and Technology," vol. 40, no. 7, pp. 52-57, 2018.

[3] J. F. Hou, H. B. Bai, and D. W. Li, "Damping capacity measurement of elastic porous wire-mesh material in wide temperature range," Journal of Materials Processing Technology, vol. 206, no. 1-3, pp. 412-418, 2008.

[4] V. Hassani, T. Tjahjowidodo, and A. D. Soetarto, "Modeling hysteresis with inertial-dependent Prandtl-Ishlinskii model in wide-band frequency-operated piezoelectric actuator," Smart Materials Research, vol. 2012, Article ID 164062, 15 pages, 2012.

[5] A. Matute, L. Paredes-Madrid, G. Moreno, F. Cárdenas, and C. A. Palacio, "A novel and inexpensive approach for force sensing based on FSR piezocapacitance aimed at hysteresis error reduction," Journal of Sensors, vol. 2018, Article ID 6561901, 16 pages, 2018.

[6] D. Zhang, F. Scarpa, Y. Ma, J. Hong, and Y. Mahadik, "Dynamic mechanical behavior of nickel-based superalloy metal rubber," Materials and Design, vol. 56, pp. 69-77, 2014.

[7] D. Zhang, F. Scarpa, Y. Ma, K. Boba, J. Hong, and H. Lu, "Compression mechanics of nickel-based superalloy metal 
rubber," Materials Science and Engineering A, vol. 580, pp. 305-312, 2013.

[8] G. F. Jiang and G. He, "Enhancement of the porous titanium with entangled wire structure for load-bearing biomedical applications," Materials and Design, vol. 56, pp. 241-244, 2014.

[9] J. L. Hu, Q. Du, J. Gao, J. Kang, and B. Guo, "Compressive mechanical behavior of multiple wire metal rubber," Materials and Design, vol. 140, pp. 231-240, 2018.

[10] H. Wang, J. A. Rongong, and G. R. Tomlinson, "Nonlinear static and dynamic properties of metal rubber dampers," in Proceedings of International Conference on Noise and Vibration Engineering, pp. 1301-1316, Leuven, Belgium, September 2010.

[11] Y. Ma, Q. Zhang, D. Zhang, F. Scarpa, D. Gao, and J. Hong, "Size-dependent mechanical behavior and boundary layer effects in entangled metallic wire materialsystems," Journal of Materials Science, vol. 52, no. 7, pp. 3741-3756, 2017.

[12] B. H. Cai, J. Yu, and Y. H. Bai, "Design of elastic damping vibration on warship piping and its testing research," Ship Science and Technology, vol. 11, pp. 61-64, 2011.

[13] H. R. Ao, H. Y. Jiang, and S. G. Wang, "Research on vibration isolation function of metal rubber damper for supporting engine pipe line," Journal of Machine Design, vol. 20, pp. 14-17, 2003.

[14] H. B. Bai, C. H. Lu, and F. L. Cao, Material and Engineering Application of Metal Rubber, Science Press, Beijing, China, 2014.

[15] H. B. Bai and P. L. Zhang, Hysteresis Vibration System and Its Engineering Application, Science Press, Beijing, China, 2002.

[16] S. J. Zhu and L. He, Vibration Control of Ship Machinery, National Defense Industry Press, Beijing, China, 2006.

[17] D. P. Dai, Engineering Application of Damping Technology, Tsinghua University Press, Beijing, China, 1991.

[18] B. A. Olmos and J. M. Roesset, "Evaluation of the half-power bandwidth method to estimate damping in systems without real modes," Earthquake Engineering and Structural Dynamics, vol. 39, no. 14, pp. 1671-1686, 2010.

[19] G. A. Papagiannopoulos and G. D. Hatzigeorgiou, "On the use of the half-power bandwidth method to estimate damping in building structures," Soil Dynamics and Earthquake Engineering, vol. 31, no. 7, pp. 1075-1079, 2011.

[20] Q. Tan and G. He, "3D entangled wire reinforced metallic composites," Materials Science and Engineering A, vol. 546, pp. 233-238, 2012.

[21] W. Peng, H. B. Bai, and J. Zheng, "A new method for testing damping capacity of metal rubber materials," Journal of Experimental Mechanics, vol. 19, no. 3, pp. 342-346, 2004. 


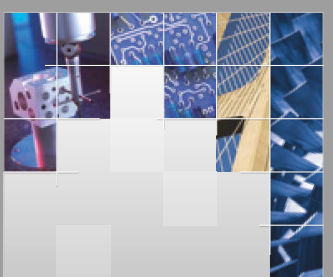

\section{Enfincering}
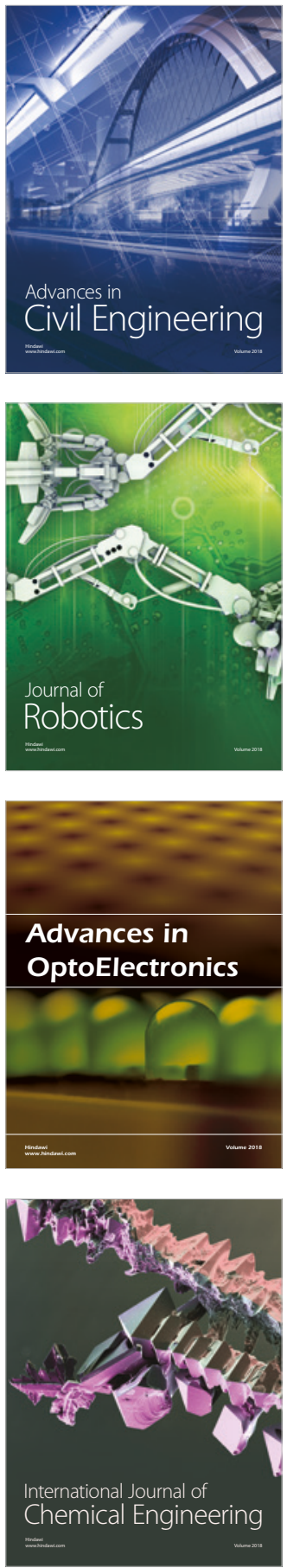

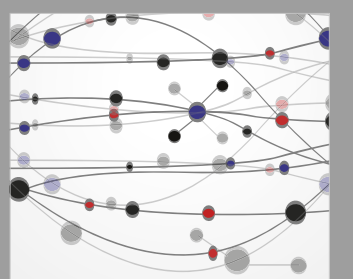

\section{Rotating \\ Machinery}

The Scientific World Journal

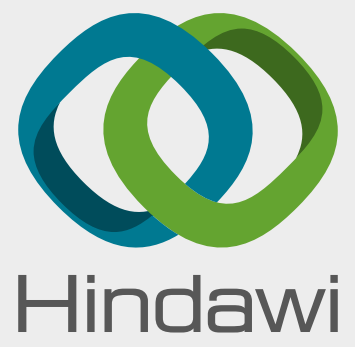

Submit your manuscripts at

www.hindawi.com
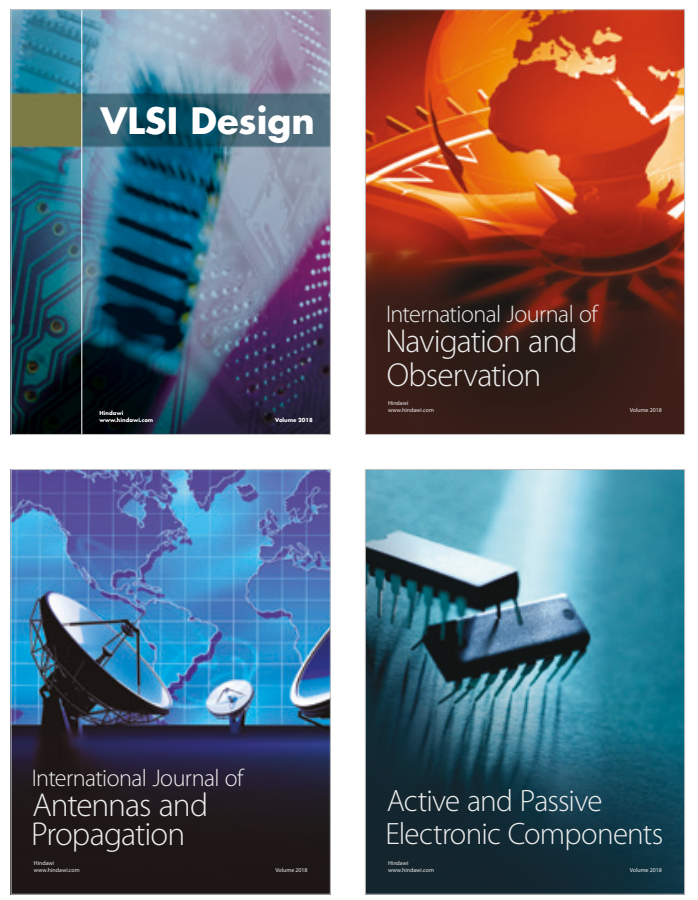
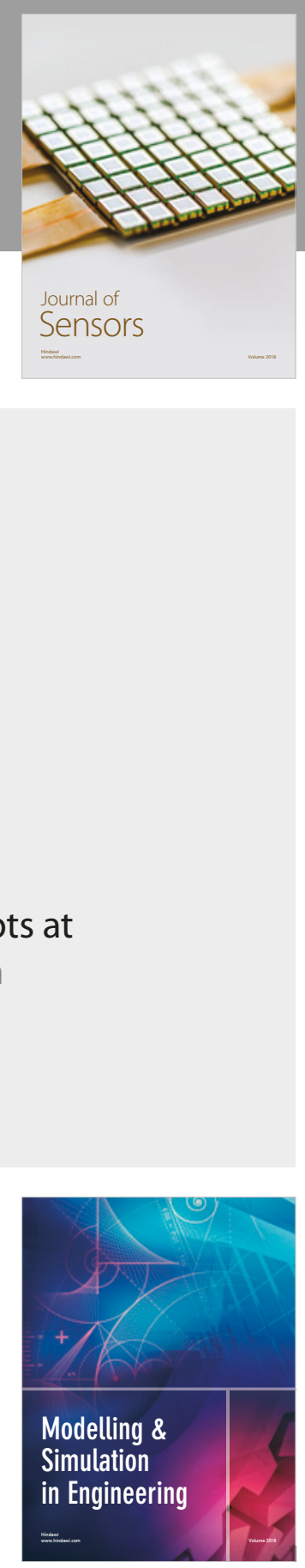

\section{Advances \\ Multimedia}
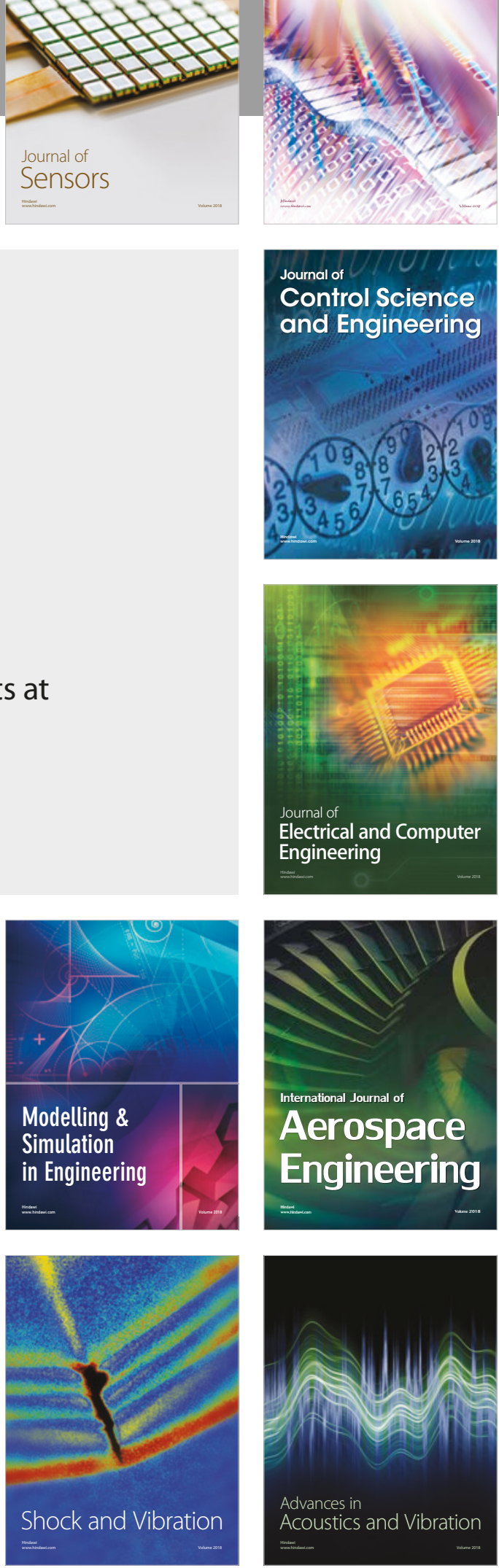